\title{
Sustentabilidade e condições de vida em áreas urbanas: medidas e determinantes em duas regiōes metropolitanas brasileiras ${ }^{*}$
}

\begin{abstract}
This paper develops an Urban Sustainability Index System as part of a broader effort to provide better quality data and statistical analysis for local environmental decision-making. We show that urban sustainability can be measured in a comprehensive and synthetic way. In providing fair comparison across cities while keeping sensibility to local context, this index system can be used by policy-makers as a powerful tool to identify critical trends and policy gaps. This Urban Sustainability Index System has been applied to 57 cities in the metropolitan areas of São Paulo and Belo Horizonte, Brazil. The results indicate two different paths in relation to sustainability. The first is characterized by a gap between environmental quality and human development, leading away from sustainability. It is followed by the core cities and highly industrialized ones in both metropolitan areas. The second leads towards sustainability and is followed by a heterogeneous group of cities in both regions.
\end{abstract}

Key words: urban sustainability, sustainability index, São Paulo metropolitan area, Belo Horizonte metropolitan area.

\section{Resumo}

Este artigo é parte de um esforço acadêmico recente de criação de ferramentas de mensuração do fenômeno sustentabilidade. Apresenta sistema de índices de sustentabilidade urbana, aplicando-o a 57 municípios das Regiōes Metropolitanas de São Paulo e Belo Horizonte, Brasil. O sistema de índices foi criado considerando, principalmente, três fatores: a) incorporação das dimensões econômica, ecológica, políticosocial, espacial (ou territorial) e de planejamento; b) adoção da escala urbana/metropolitana; e c) incorporação de indicadores institucionais capazes de avaliar a capacidade do sistema político e da sociedade em oferecer respostas aos desafios presentes e futuros da sustentabilidade. Os resultados obtidos mostram a existência de dois padrões claros nas duas regiôes. O primeiro, de desequilíbrio entre qualidade ambiental e desenvolvimento humano, verificado no município central e nos municípios fortemente industrializados de ambas as regiōes. O segundo, mais sustentável, de equilíbrio entre qualidade ambiental e desenvolvimento humano, verificado em municípios com diferentes perfis em ambas as regiōes.

Palavras-chave: sustentabilidade urbana, indicadores de sustentabilidade, Região Metropolitana de São Paulo, Região Metropolitana de Belo Horizonte. 


\section{Sustentabilidade urbana: significado e medidas}

A idéia de sustentabilidade urbana é uma ferramenta poderosa na aproximação das temáticas ambiental e urbana, a qual se consolidou ao longo da década de 90 .

A oposição entre o ambiental e o urbano, o primeiro visto como pertencente ao reino do natural e o segundo como a expressão do não-natural, dominou o pensamento ambientalista em seus primórdios. Se nas raízes do ambientalismo e em suas vertentes preservacionista e conservacionista abre-se um enorme ponto cego em relação à questão urbana (Costa, 1995), a mudança de enfoque na definição da questão ambiental em direção à sustentabilidade nos anos 80 permitiu uma aproximação das temáticas.

Temas como desenvolvimento urbano, controle da poluição atmosférica e hídrica nas cidades, utilização sustentável de recursos naturais e conservação de espaços verdes no interior dos espaços urbanos tiveram forte presença na agenda das principais organizaçōes multilaterais voltadas para o desenvolvimento e para a questão urbana nos anos 90, bem como em seus critérios para aprovação de projetos e concessão de financiamentos (UNCHS, 1988; The World Bank, 1991; United Nations, 1992; UNDP, 1992; UNDP/UNCHS/The World Bank, 1994).

No caso das Conferências Internacionais, é sintomática a inclusão da questão ambiental no espaço urbano como um dos cinco grandes temas do Hábitat II (conferência internacional da ONU sobre as cidades), bem como a inclusão das temáticas cidades e poder local entre as principais questōes discutidos na Rio 92 (conferência internacional da ONU sobre meio ambiente e desenvolvimento) e sistematizados na Agenda 21.

\footnotetext{
* CEDEPLAR/UFMG y Universidade Cândido Mendes (Brasil). E-mail: taniabrg@uol.com.br

* Agradecemos à FAPEMIG (Fundação de Apoio à Pesquisa do Estado de Minas Gerais) pelo apoio financeiro concedido. Son coautores de este artículo Fausto Brito (CEDEPLAR/UFMG), Ana Paula Gonçalves de Freitas (CEDEPLAR/UFMG) y Denise Helena França Marques (CEDEPLAR/UFMG). Enviado el 9 de septiembre de 2004, aprobado el 1 de junio de 2006.
}

Recentemente, o Millennium Ecosystem Assessment, ou Avaliação Ecossistêmica do Milênio ${ }^{1}$, incluiu o sistema urbano entre as 10 categorias de sistemas utilizadas para apresentar seus resultados (Millennium Ecosystem Assessment, 2005).

A Agenda 21 Brasileira elegeu o tema cidades sustentáveis como um dos seis pilares sobre os quais se sustenta a construção da sustentabilidade ambiental, social e econômica do país (Novaes, 2000).

Como foi enunciado, a idéia de sustentabilidade urbana corporifica a convergência entre o ambiental e o urbano. Mas, a despeito da crescente importância e amplo uso do conceito, este está longe de possuir significado consensual. Segundo Ferreira (1998: 59), "o conceito torna-se um ponto de referência obrigatório dos debates acadêmicos, políticos e culturais; na verdade, passa a ser uma idéia poderosa, sobre a ordem social desejável e um campo de batalha simbólico sobre o significado desse ideal normativo".

O que há subjacente às diversas versões do que seria o desenvolvimento sustentável urbano é uma disputa pelo estabelecimento da "verdade" no que tange a esse conceito. Verdade entre aspas, pois esta nunca é absoluta, é sempre socialmente construída através de uma disputa de poder. Segundo Foucault (1996:13) os discursos em si não são verdadeiros ou falsos, o que existe é "um combate pela verdade [...] pelo conjunto das regras segundo as quais se distingue o verdadeiro do falso e se atribui ao verdadeiro efeitos específicos de poder". Para Bourdieu (1996: 127), "quando se trata do mundo social, as palavras criam as coisas, já que criam o consenso sobre a existência e o sentido das coisas, o senso comum". Nesse contexto, "se existe uma verdade, é que a verdade é um lugar de lutas".

Ao aplicar esta discussão à questão da sustentabilidade urbana, Acselrad (1999) alerta que a forma pela qual se articulam conceitos e se constroem

${ }^{1}$ A Avaliação Ecossistêmica do Milênio foi conduzida sob o patrocínio das Naçôes Unidas, com o objetivo de avaliar as conseqüências das mudanças nos ecossistemas sobre o bem estar humano, e estabelecer uma base científica que fundamentasse as ações necessárias para assegurar conservação e uso sustentável dos ecossistemas e suas contribuições para o bem estar humano. 
matrizes discursivas que articulam as questões ambiental e urbana fazem parte de um jogo de poder em torno da apropriação do território e de seus recursos, que têm por objetivo legitimar ou deslegitimar discursos e práticas sociais. Partindo daí, o autor investiga os diversos discursos sobre a sustentabilidade urbana e identifica matrizes discursivas de representação de forma a tornar claro o que está sendo disputado, quais são as visões de futuro de cidade em disputa, o que se fazer durar, para quê e para quem, tornando transparentes as diferentes propostas políticas existentes por trás dos rótulos meio ambiente e sustentabilidade. São três as matrizes discursivas de sustentabilidade urbana identificadas pelo autor. A primeira, representação tecno-material da cidade, combina modelos de racionalidade energética com modelos de equilíbrio metabólico e reduz a sustentabilidade urbana a seu aspecto estritamente material. A segunda, representação da cidade como espaço da qualidade de vida, combina modelos de pureza, de cidadania e de patrimônio e remete a sustentabilidade a um processo de construção de direitos que possam equacionar as externalidades negativas responsáveis pela insustentabilidade urbana. A terceira matriz, centrada na reconstituição da legitimidade das políticas urbanas, combina modelos de eficiência e eqüidade, além de remeter a sustentabilidade à construção de pactos políticos capazes de reproduzir suas próprias condições de legitimidade.

Compreender que a sustentabilidade urbana é antes uma idéia em construção e disputa que uma definição acabada, é fundamental para compreender o papel no estabelecimento de sua "verdade" dos esforços em torná-la mais operacional e mensurável, como a criação de indicadores. Portanto, é necessário explicitar aqui o que se entende por sustentabilidade ambiental.

Eximimos-nos, contudo, de efetuar comparaçôes entre o conteúdo aqui atribuído à idéia de sustentabilidade urbana e outras definiçôes importantes no estabelecimento da "verdade" sobre o tema -como as provenientes da Agenda 21 (United Nations, 1992), do Habitat I (UNCHS, 1988), dentre outras- uma vez que esta se tornaria por demais extensa no contexto deste artigo.

Optamos por utilizar, dentre os vários conteúdos atribuidos à idéia de sustentabilidade urbana, uma que estivesse em consonância com a terceira das matrizes discursivas de sustentabilidade urbana identificadas por Acselrad (1999). Nossa escolha recaiu sobre a definição do Urban World Forum (2002), que define sustentabilidade urbana a partir do estabelecemineto de um conjunto de prioridades, são elas: superar a pobreza, promover equidade, melhorar a segurança ambiental e prevenir a degradação, estar atento à vitalidade cultural e ao capital social para fortalecer a cidadania e promover o engajamento cívico.

A esta definição adicionamos as observações feitas pro McGranahan e Satterthwaite (2002) e Miller e Small (2003) de que para ser considerada sustentável, não é suficiente que uma cidade confira a seus habitantes condições ambientais equilibradas, mas que o faça sem gerar externalidades negativas para outras regiōes (próximas ou distantes) e para as gerações futuras. Isso implica em levar em conta não apenas a escala local, ou intra-urbana, da sustentabilidade, mas também considerar a escala regional, constituída pela cidade e suas relaçôes com o entorno, e a escala global, constituída pelos seus impactos sobre os problemas ambientais globais, como o efeito estufa, e por questôes relativas aos impactos agregados da rede mundial de grandes cidades sobre o planeta.

Apesar dos esforços recentes empreendidos na sistematização de informações para a gestão ambiental urbana em cidades de diversos países e regiōes, o desafio de lidar com a carência de informações sistematizadas sobre a questão ambiental urbana ainda é de grande monta. Não é por outra razão que grande parte das decisões tomadas por órgãos públicos, na área ambiental, se dá a partir de informaçôes imprecisas que tornam-se "certezas" fragilmente construídas.

Da necessidade de provisão de informação de qualidade para guiar a tomada de decisões relativas à sustentabilidade, surgiram desde o final da década dos 80 , várias iniciativas de construção de índices e indicadores, a maior parte delas aplicadas à escala nacional. Tais iniciativas possuíam em comum o objetivo de fornecer subsídios à formulação de políticas, bem como monitorar o progresso no cumprimento de acordos internacionais e orientar a tomada de decisão por atores públicos e privados. No seu conteúdo procuram descrever e mensurar a interação entre a atividade antrópica e o meio am- 
biente, conferindo à idéia de sustentabilidade maior operacionalidade e funcionalidade.

Em geral, tais iniciativas tomam por base o modelo de pressão-estado-resposta (OECD, 1994), ou sua variante força motora-estado-resposta (United Nations, 2001). Neste modelo, os indicadores de estado buscam descrever a situação presente, física ou biológica, dos sistemas naturais. Os indicadores de pressão, ou força motora, tentam avaliar e medir as pressões exercidas pelas atividades antrópicas sobre os sistemas naturais ou as forças motoras que geram tais pressões, respectivamente. Os chamados indicadores de resposta procuram avaliar a qualidade das políticas e acordos formulados para responder, ou seja, minimizar os impactos antrópicos.

Um marco dentre tais iniciativas foi a criação pela Comissão de Desenvolvimento Sustentável das Nações Unidas de um Grupo de Trabalho de Indicadores de Desenvolvimento Sustentável. O objetivo de tal comissão foi construir indicadores acessíveis aos tomadores de decisão que pudessem auxiliar os países nos seus esforços de medir o progresso rumo ao desenvolvimento sustentável. A metodologia básica proposta evoluiu de uma abordagem força motora-estado-resposta para uma abordagem baseada em temas e sub-temas de desenvolvimento sustentável a partir da experiência acumulada nos testes e nas avaliações por experts. Alguns países participantes da etapa de testes concluíram que a abordagem força motora-estadoresposta, embora adequada para a dimensão ambiental, não se mostrou adequada para as dimensões social, econômica e institucional do desenvolvimento sustentável (United Nations, 2001).

Outra iniciativa digna de nota, esta mais específica em relação ao urbano e à escala local, é a do Programa de Indicadores Urbanos do Habitat, tem por objetivo servir de base para o estabelecimento de uma Rede Mundial de Observatórios Urbanos, bem como para a avaliação e controle da implementação dos programas do Habitat e da Agenda 21. A iniciativa contempla indicadores relativos a cinco temas: abrigo (shelter); desenvolvimento social e erradicação da pobreza; gestão ambiental; desenvolvimento econômico; governança (UNCHS, 2004).

$\mathrm{Na}$ América Latina, uma iniciativa nesse sentido foi a criação pela CEPAL da Rede de Indicadores de
Desenvolvimento Sustentável, como o objetivo de apoiar os países latino americanos nos processos de construção e implementação de indicadores de desenvolvimento, promovendo também intercâmbio e troca de experiências. Entretanto, tal iniciativa ainda é insipiente. No Brasil, destaca-se a iniciativa Indicadores de Desenvolvimento Sustentável-Brasil 2004, do IBGE (Instituto Brasileiro de Geografia e Estatística), que calcula indicadores de sustentabilidade nas dimensões ambiental, social, econômica e institucional para os estados da federação (IBGE, 2004).

Recentemente, em junho de 2006, o Banco Mundial anunciou durante o III Urban Fórum, uma proposta de facilitar o desenvolvimento de indicadores urbanos padronizados com uma forte dimensão de sustentabilidade. Nos dois primeiros anos do projeto serão construídos indicadores em parcerias com 5 cidades-piloto: Belo Horizonte e São Paulo, no Brasil, Bogotá na Colômbia e Toronto e Vancouver no Canadá.

A consolidação de índices sintéticos como medida de desenvolvimento econômico e social, como o Produto Interno Bruto (PIB) e o Índice de Desenvolvimento Humano (IDHM), impóe a construção de medidas de sustentabilidade que possam dialogar com esses indicadores historicamente consagrados. Desta forma, os índices de sustentabilidade em geral, e os índices de sustentabilidade urbana em particular, podem ser considerados como parte de uma quarta geração, em construção, dos índices de desenvolvimento ${ }^{2}$.

Dentre as dificuldades metodológicas comuns na construção de indicadores de sustentabilidade, urbanos ou não, destacam-se a formulação conceitual

\footnotetext{
${ }^{2}$ A primeira geração de tais índices tem como representante principal o Produto Interno Bruto per capta (PIB per capta). A segunda geração tem como representante principal o Índice de Desenvolvimento Humano (IDH), proposto pelo PNUD com o objetivo de incorporar aspectos da vida humana, como educação e longevidade, não considerados pelo primeiro. A terceira geração de indicadores é composta por índices que tem por objetivo aperfeiçoar o IDH, como o IDG (Índice de Desenvolvimento ajustado a Gênero) e o IPH (Índice de Pobreza Humana), ambos do PNUD; o ICV (Índice de Condições de Vida), produzido para os municípios brasileiros pelo IPEA e Fundação João Pinheiro; e o IPRS (Índice Paulista de Responsabilidade Social), produzido para os municípios paulistas pela Fundação Seade.
} 
apropriada, a tradução operacional em variáveis, a obtenção de dados fidedignos e o seu tratamento estatístico adequado. Dada a inexistência de consenso em relação aos conceitos de sustentabilidade e de qualidade ambiental, o processo de escolha das variáveis a serem utilizadas na suas mensuraçōes aca$\mathrm{ba}$, muitas vezes, sendo mais uma função da disponibilidade de dados do que uma decorrência do conceito, o que compromete o rigor teórico das relaçôes de causalidade encontradas entre os diferentes indicadores. A carência de informaçôes sistemáticas tem sido um problema recorrente para todos aqueles que trabalham com indicadores ambientais e de sustentabilidade (Environmental Sustainability Indicators, 2002; Esty e Porter, 2002; United Nations, 2001; Herculano, 1998; Isla, 1998).

\section{O Sistema de Índices de Sustentabilidade Urbana (SISU)}

O Sistema de Índices de Sustentabilidade Urbana (SISU) tem por objetivo fornecer uma ferramenta de análise da sustentabilidade nos aglomerados metropolitanos brasileiros.

Faz parte, portanto, do esforço acadêmico desenvolvido recentemente, no Brasil e em outros países, para a construção de índices e indicadores de sustentabilidade. Desse modo, refletindo o estado da arte, nacional e internacional, na elaboração desses índices e indicadores, o sistema apresentado neste artigo, certamente, ainda está sujeito ao aperfeiçoamento inerente ao debate acadêmico e com todos os politicamente interessados.

Como poderia se esperar, a construção do sistema de índices deparou, inicialmente, com o problema de tornar comparáveis os dados, geralmente, de diferentes fontes, produzidos em escalas distintas, com cobertura espacial e distribuição temporal diversas. Compatibilizar essas informações não é uma tarefa simples, tornando-se mais complexa quando, muitas vezes, não se dispõe de informaçōes e necessitase construir proxies adequadas. Essas limitaçōes iniciais, longe de se transformarem em impedimentos, acabaram servindo como desafios, respondidos sem se perder o necessário rigor que o tema sustentabilidade exige.

\subsection{O Sistema de Indices de Sustentabilidade Urbana: concepção e composição}

A abordagem escolhida foi a da construção de um sistema de índices temáticos, como adotado pelas versões mais recentes do Programa de Indicadores Urbanos do Habitat (UNCHS, 2004), dos Indicadores de Desenvolvimento Sustentável das Nações Unidas (United Nations, 2001) e do Indicadores de Desenvolvimento Sustentável-Brasil 2004 (IBGE, 2004), em lugar da construção de um único índice síntese. Isto porque, se por um lado, os índices sintéticos, ou compostos, possuem a clara vantagem de uma comunicação ágil, por outro, são muitas as críticas a eles dirigidas. Argumenta-se, com propriedade, que indicadores sintéticos reduzem a dimensão das diferenças e escondem desigualdades e heterogeneidades internas às unidades de análise (UNDP, 1992; Herculano, 2000; Fundação Seade, 2002). De fato, testes estatísticos realizados pelos autores com o conjunto inicial de variáveis coletadas pelo projeto de pesquisa que deu origem a este artigo, revelaram a baixa sensibilidade de um índice sintético para discriminar, significativamente, as diferentes unidades de análise no contexto dos indicadores aqui calculados.

Em consonância com a definição de sustentabilidade urbana aqui adotada (item 1), o SISU é composto por três índices temáticos: índice ambiental, índice de capacidade político-institucional e índice de desenvolvimento humano municipal. Cada índice mede o progresso em relação a um conjunto de objetivos relacionados à sustentabilidade urbana. O primeiro índice mede as prioridades de sustentabilidade urbana relativas à melhoria $\mathrm{da}$ segurança ambiental e à prevenção da degradação. $\mathrm{O}$ segundo mede as prioridades de sustentabilidade urbana relativas ao fortalecimento da cidadania e promoção do engajamento cívico. O terceiro mede as prioridades de sustentabilidade urbana relativas à superação da pobreza e promoção da equidade.

Os índices ambiental e capacidade políticoinstitucional foram elaborados e construídos pelos autores no âmbito da pesquisa aqui mencionada. $\mathrm{O}$ índice de desenvolvimento humano municipal é aquele produzido pelo IBGE/FJP/PNUD, que consiste em uma aplicação da metodologia do IDH (Índice de Desenvolvimento Humano) do Programa 
de Desenvolvimento das Naçôes Unidas (UNDP) para o contexto dos mais de cinco mil municípios brasileiros.

Os índices temáticos são formados por um conjunto de indicadores, que por sua vez são compostos por uma série de variáveis relativas aos fenômenos estudados, observadas diretamente ou como proxies.

A escolha preliminar dos indicadores e variáveis foi baseada nas matrizes de sustentabilidade propostas no projeto Biodiversidade, População e Economia (Paula, 1997), nas variáveis e indicadores utilizados no ESI (Environmental Sustainability Index) (Environmental Sustainability Index, 2002) e nos indicadores do Programa de Indicadores Urbanos do Habitat (UNCHS, 2004). Obviamente, foi necessário realizar adaptações importantes de modo a adequar os indicadores e variáveis à escala local e à realidade metropolitana. Os critérios considerados para tanto foram: a) relevância, isto é, capacidade da variável em traduzir o fenômeno; b) aderência local, isto é, a capacidade da variável (indicador) em captar fenômeno produzido ou passível de transformação no plano local; e c) disponibilidade, cobertura e atualidade dos dados.

A escolha final das variáveis foi feita através de abordagem indutiva, por meio de análise de correlação e análise multivariada de componentes principais (ACP). As variáveis que mostraram alta correlação com outras variáveis contidas no indicador foram excluídas. $\mathrm{Na} \mathrm{ACP}$, aquelas que mostraram baixo poder explicativo da variância total foram excluídas.

O Índice Ambiental é composto por oito indicadores. Quatro deles medem a qualidade do ambiente no momento presente, tanto em relação ao ambiente natural -recursos hídricos e cobertura vegetal-quanto em relação ao ambiente construído -serviços sanitários e qualidade da habitação-e se relacionam tanto aos objetivos de segurança ambiental quanto aos objetivos de prevenção da degradação. Os outros quatro indicadores se relacionam inversamente com o estresse ambiental gerado pela intervenção antrópica sobre as áreas urbanas e são uma medida dos objetivos de segurança ambiental e prevenção da degradação.
Os indicadores utilizados em relação à qualidade do ambiente foram:

Recursos hídricos. A qualidade dos recursos hídricos é um dos aspectos mais importantes em relação aos objetivos de segurança ambiental urbana, uma vez que o comprometimento dos recursos hídricos fragiliza os sistemas naturais e compromete as condições de vida da população local. É também um aspecto importante em relação à prevenção da degradação ambiental, pois uma alta qualidade dos recursos hídricos indica sucesso na prevenção da degradação deste recurso natural básico. O cálculo do indicador de qualidade dos recursos hídricos foi feito usando metodologia elaborada pelos órgãos ambientais estaduais das regiōes metropolitanas estudadas, que permitem a comparabilidade dos resultados. Este indicador é composto de uma série de variáveis físicoquímicas, tais como temperatura, turbidez, $\mathrm{Ph}$, condutividade, demanda química de oxigênio, demanda bioquímica de oxigênio, fenóis, oxigênio dissolvido, mercúrio, níquel, óleos e graxas, amônia, dentre outros. Os dados utilizados na construção dos indicadores são provenientes dos órgãos ambientais estaduais.

Cobertura vegetal. A preservação da cobertura vegetal também é de importância central para os objetivos de segurança ambiental e prevenção da degradação, uma vez que a vegetação original não apenas é, por si só, recurso natural básico, como também é suporte para a biodiversidade faunística e age como uma proteção natural contra a poluição atmosférica e alterações microclimáticas. O indicador de cobertura vegetal foi medido através da relação entre a cobertura vegetal remanescente e a área de domínio da cobertura original, a partir dos dados obtidos através de processamento de imagens de satélite e estudos da Fundação SOS Mata Atlântica.

Um terceiro indicador de importância chave em relação à qualidade do ambiente natural, a qualidade do ar, não foi incorporado ao índice por ausência de dados de monitoramento atmosférico confiáveis para a grande maioria dos municípios para os quais calculamos o indicador. No entanto, dentre os indicadores 
de estresse ambiental, dois são boas proxies da pressão exercida sobre a qualidade do ar, a saber, pressão industrial e pressão veicular. Desta forma, a ausência de um indicador de qualidade do ar não compromete a validade do índice ambiental.

Esta versão também não incorpora indicador de qualidade do solo, também de importância chave em relação à qualidade do ambiente natural, mais uma vez por falta de dados para a maior parte dos municípios estudados.

- Serviços sanitários. Este indicador é de importância central para os objetivos de segurança ambiental e prevenção da degradação. Água potável é uma das necessidades humanas mais básicas e o acesso a ela implica em redução de doenças de veiculação hídrica e em aumento da qualidade de vida. A falta de saneamento básico é um problema grave de saúde pública, responsável por inúmeras doenças e mortes, além de ser uma ameaça aos recursos hídricos. $\mathrm{O}$ indicador toma como proxy o acesso à rede pública de fornecimento de água, instalação sanitária adequada e acesso à coleta regular de resíduos sólidos urbanos, baseado no pressuposto que acesso a infra-estrutura sanitária adequada implica muito provavelmente em acesso a água potável, coleta de esgoto e disposição adequada de resíduos sólidos. Os dados utilizados na construção do indicador provém do Censo Demográfico de 2000 (IBGE, 2000).

- Habitação adequada. Este indicador é de importância central para o objetivo de segurança ambiental, no que se refere à segurança do ambiente construído, pois habitação inadequada implica em exposição a maiores riscos de morbidade e mortalidade. Além disso, diz respeito à necessidade humana básica de abrigo. $\mathrm{O}$ indicador toma como proxy o inverso da taxa de habitaçôes sub normais. Habitações sub-normais correspondem a domicílios localizados em favelas e cortiços. Os dados utilizados na construção do indicador provém do Censo Demográfico de 2000 (IBGE, 2000).

Os indicadores utilizados para medir o estresse ambiental gerado pela pressão antrópica foram:
Pressão industrial. Este indicador mede a pressão exercida pelas atividades industriais sobre o ambiente e a qualidade de vida da população e se relaciona aos objetivos de seguraça ambiental e prevenção da degradação. Atividades industriais estão as principais fontes pontuais de poluição atmosférica, hídrica e do solo. A intensidade energética -energia consumida sobre o valor da produção em reaisfoi considerada proxy da pressão industrial, acompanhando a literatura internacional que considera que indústrias com maior potencial poluidor apresentam, em geral, menor eficiência energética. Os dados utilizados na construção do indicador são provenientes das empresas fornecedoras de energia elétrica.

- Pressão intra-domiciliar. Este indicador mede a pressão exercida pelos domicílios superpovoados. Domicílios superpovoados implicam em reduzido espaço por pessoa e no uso de um único cômodo para cozinhar, dormir e realizar outras atividades domésticas, o que é considerado pela literatura como frequentemente associado a alto risco para a saúde humana (UNCHS, 2004). Também representam uma pressão para a construção de novas unidades residenciais, uma vez que devido ao baixo poder aquisitivo da população que demanda as novas unidades residenciais estas serão, em geral, construídas em favelas e outras ocupaçôes irregulares, representando portanto um potencial para o crescimento do número de domicílios em condições subnormais. $\mathrm{O}$ indicador foi medido através de duas variáveis, média de residentes por cômodos e a média de moradores por domicílio. Os dados utilizados na construção do indicador provém do Censo Demográfico de 2000 (IBGE, 2000).

Pressão por consumo doméstico. Este indicador mede a pressão exercida por domicílios de alto poder aquisitivo. As metrópoles brasileiras, por sua heterogeneidade, combinam desafios à sustentabilidade advindos da pobreza-como favelas, domicílios superpovoados, domicílios desprovidos de infra-estrurura básica- com desafios provenientes da riqueza -como a existência de uma parcela da população com 
altos padrões de consumo e uso intensivo de recursos naturais. A intensidade no uso energético domiciliar, medida pelo consumo energético domiciliar per capta, foi tomada como próxy da pressão por consumo doméstico. Tal escolha se deu em função de um alto consumo de energia elétrica domiciliar estar via de regra relacionado à utilização intensiva de aparelhos elétricos e eletrônicos, o que por sua vez denota um alto padrão de consumo. Os dados utilizados na construção do indicador são provenientes das empresas de fornecimento de energia elétrica.

Pressão automotiva. Este indicador mede a pressão exercida pelo número de veículos em circulação. Veículos são a principal fonte de emissão de poluentes atmosféricos em regiōes densamente urbanizadas. O número de veículos per capta é tomado como proxy da pressão automotiva. As informaçōes para a construção deste indicador são provenientes da base de dados do governo estadual usada na cobrança de impostos sobre veículos automotivos.

O Índice de Capacidade Político-Institucional avalia a capacidade do sistema político-institucional e $\mathrm{da}$ sociedade de enfrentar os desafios da sustentabilidade urbana e oferecer respostas aos problemas a ela relacionados. Está relacionado às prioridades de sustentabilidade urbana relativas ao fortalecimento da cidadania e promoção do engajamento cívico. Ele é formado por quatro indicadores: autonomia político-administrativa; gestão pública municipal; gestão ambiental municipal; informação e participação política. Como mostra Environmental Sustainabiliy Index (2002), para que a sustentabilidade ambiental possa ser atingida, é necessário dotar as administrações locais de capacidade social e institucional, assim como construir padrões sociais de habilidades, atitudes e trabalho, para que se possa promover mudanças efetivas ao meio ambiente. O índice de Capacidade Política-Institucional foi medido através dos seguintes indicadores:

Autonomia político-fiscal. Este indicador capta o grau de independência fiscal e política do governo local, que interfere diretamente em sua capacidade de executar políticas públicas e estabelecer suas prioridades. Considerou-se como proxies a autonomia fiscal e o peso eleitoral. Autonomia fiscal é calculada como a relação entre arrecadação própria e os recursos advindos das transferências intergovernamentais, expressando o grau de independência do governo local na obtenção de receitas públicas, o qual condiciona em grande parte o grau de autonomia para estabelecer prioridades. $O$ peso eleitoral é calculado como a relação entre o número de eleitores do município sobre o número de eleitores do estado e a população do município sobre a população do estado, aqui tomado como uma proxy da influência do município no processo eleitoral, visto que o comparecimento às eleições no Brasil é obrigatório e a prática de ser eleitor em município outro que o da residência principal significativo em algumas regiōes metropolitanas. Os dados utilizados na construção dos indicadores provém de banco de dados da Secretaria do Tesouro Nacional e dos Tribunais Eleitorais Estaduais.

Gestão pública municipal. Este indicador capta a eficiência da máquina pública municipal e a existência de mecanismos de tomada de decisão democráticos que facilitem o engajamento cívico e fortaleçam a participação cidadã. $\mathrm{O}$ indicador toma como proxies: porcentagem de funcionários com educação superior; grau de informatização da máquina pública local; existência de instrumentos de gestão urbana; existência e regularidade no funcionamento dos Conselhos Municipais de Desenvolvimento Urbano e de Habitação. As três primeiras proxies medem a eficiência da máquina pública e a última mede a existência e funcionamento efetivo de mecanismos de gestão urbana democrática. Os dados utilizados na construção do indicador são provenientes da Pesquisa de Informações MunicipaisGestão Pública (IBGE, 2004).

Gestão ambiental municipal. Este indicador capta a eficiência da máquina pública municipal na gestão ambiental. $\mathrm{O}$ indicador toma como proxies a existência e a regularidade das reuniōes do Conselho de Meio Ambiente e as 
unidades de conservação municipal por 100 mil habitantes. As primeira proxy mede a existência e funcionamento efetivo de mecanismos de gestão ambiental democrática e a segunda mede um resultado específico da política pública local de conservação de recursos naturais. Os dados utilizados na construção do indicador são provenientes da Pesquisa de Informações Municipais-Gestão Pública (IBGE, 2004).

- Informação e participação política. Este indicador capta o grau de engajamento cívico e da participação cidadã. Toma como proxies: presença de ONGs ambientalistas registradas no Cadastro Nacional de ONGs Ambientalistas; participação político eleitoral - proporção de votos válidos nas últimas eleições municipais; peso da imprensa escrita e falada local na imprensa estadual (número de jornais ou rádios do município sobre o número de jornais ou rádios total no estado). Uma opinião pública bem informada é pré-requisito para o engajamento cívico. A participação político-eleitoral é uma boa medida do grau de interesse e envolvimento da população no governo $\operatorname{local}^{3}$. A presença de organizações ambientalistas legalizadas e acreditadas indica exercício de cidadania ambientalizada e engajamento cívico em questôes relacionadas à sustentabilidade. Os dados utilizados na construção do indicador são provenientes da Pesquisa de Informações Municipais-Gestão Pública (IBGE, 2004) e de banco de dados dos Tribunais Eleitorais Estaduais.

O Índice de Desenvolvimento Humano Municipal-IBGE/FJP/PNUD-foi incorporado ao sistema de índices por sua credibilidade, disponibilidade e atualização para todos os municípios estudados. Ele mede as prioridades de sustentabilidade urbana relativas à superação da pobreza e promoção da equidade.

\footnotetext{
${ }^{3}$ Votos válidos são aqueles dados a candidatos efetivos, excluindo votos em branco ou nulos. O comparecimento às eleições no Brasil é obrigatório. A não participação e desinteresse no processo eleitoral são medidos pela proporção de votos válidos, uma vez que votos em branco e nulos são a forma existente de não participação eleitoral.
}

O IDHM mede em escala municipal os mesmos fenômenos medidos pelo consagrado Índice de Desenvolvimento Humano. Para a avaliação da dimensão educação, o cálculo do IDH municipal considera dois indicadores: taxa de alfabetização de pessoas acima de 15 anos de idade (com peso dois) e a taxa bruta de frequiência à escola (com peso um). $\mathrm{O}$ primeiro indicador é o percentual de pessoas com mais de 15 anos capaz de ler e escrever um bilhete simples (ou seja, adultos alfabetizados). O segundo indicador é resultado de uma conta simples: o somatório de pessoas (independentemente da idade) que freqüentam os cursos fundamental, secundário e superior é dividido pela população na faixa etária de 7 a 22 anos da localidade. Para a avaliação da dimensão longevidade, o IDH municipal considera o mesmo indicador do IDH de países: a esperança de vida ao nascer. $\mathrm{O}$ indicador de longevidade sintetiza as condições de saúde e salubridade daquele local, uma vez que quanto mais mortes houver nas faixas etárias mais precoces, menor será a expectativa de vida observada no local. Para a avaliação da dimensão renda, o critério usado é a renda municipal per capita, ou seja, a renda média de cada residente no município. A sua principal desvantagem é a pequena variação que apresenta de um município para o outro nas regiões metropolitanas, não refletindo, em toda a sua amplitude, as profundas desigualdades sociais intra-municipais (IBGE/FJP/ PNUD, 2004).

\subsection{O Sistema de Indices de Sustentabilidade Urbana: metodologia de cálculo}

O primeiro passo na construção dos indicadores e índices foi tratar estatisticamente as variáveis. $\mathrm{O}$ primeiro passo para tanto foi identificar os valores extremos das variáveis (outliers) e substituí-los pelos valores correspondentes pelo limites superior do percentil 2,5\% e pelo limite inferior do percentil e $97,5 \%$, conforme o caso. Após a correção dos valores extremos, as variáveis foram padronizadas pelo método z-score, de modo a permitir a sua agregação em uma escala numérica única, facilitando as comparaçôes. Para algumas variáveis que apresentavam relação inversa com a sustentabilidade -quanto maior seu valor, pior o indicador-, a padronização foi feita a partir da fórmula inversa: subtraiu-se da média o valor da variável e o resultado foi dividido pelo desvio-padrão. 
O teste de adequação da composição dos indicadores, isto é, da adequação das variáveis que o compóem, foi realizado utilizando-se o método estatístico de análise fatorial por componentes principais (ACP). Em todos os casos, o eingevalue acumulado para o primeiro e o segundo componentes dos indicadores compostos por mais de duas variáveis foram significativos, indicando a adequação da escolha das variáveis utilizadas em sua composição. O método dos componentes principais também mostrou a não redundância dos componentes principais de cada um dos indicadores, indicando a sua sensibilidade para discriminar e classificar os municípios analisados.

Realizados os testes estatísticos, os indicadores foram padronizados pelo método dos máximos e mínimos, de forma que os seus valores variassem entre zero e um, facilitando as comparações e a comunicação dos resultados. Com isso, o município com melhor desempenho em um determinado indicador recebeu a pontuação 1 , enquanto o pior recebeu a pontuação 0 .

Os índices temáticos foram obtidos a partir da média simples dos seus respectivos indicadores. A atribuição de pesos teóricos para os indicadores foi descartada devido à ausência de consenso científico quanto à ponderação teoricamente pertinente. A atribuição de pesos através de análise fatorial por componentes principais foi descartada em função da aplicação da técnica ter retornado um número muito alto de componentes principais significativos (maiores ou iguais a 1) e a utilização da técnica de composição do peso através da soma dos quadrados dos coeficientes de todos os componentes significativos só ser indicada quando o número de unidades de análise é muito alta. Versões futuras que incorporem outras regiōes metropolitanas e aumentem o número de municípios poderão incorporar ponderação através da referida técnica.

Cabe ressaltar, no entanto, que a ausência de ponderação não compromete os resultados, uma vez que a aplicação da técnica estatística de ACP para cada indicador em separado demonstrou ser a sua composição bastante adequada, como já mencionado.

Cabe também destacar que índices de sustentabilidade consagrados, como o ESI, utilizam o mesmo critério de adoção da média não ponderada
(Environmental Sustainability Index, 2002). Em versão recente do ESI (Environmental Sustainability Index, 2005), foram realizadas uma série de testes comparando os resultados do índice não ponderado à duas ponderações alternativas, os quais demonstraram não haver diferenças substanciais entre eles, confirmando assim a adequação da opção pelo índice não ponderado.

\section{Sustentabilidade nas Regiōes Metropolitanas de São Paulo e Belo Horizonte}

As Regiōes Metropolitanas de São Paulo (RMSP) e a de Belo Horizonte (RMBH) foram escolhidas para o cálculo dos indicadores.

São Paulo foi escolhida por ser o maior aglomerado metropolitano do Brasil, o segundo maior da América Latina e o quarto do mundo. Nela concentra-se, aproximadamente, $25 \%$ de toda a atividade industrial do Brasil e cerca de $10 \%$ da sua população.

Já a escolha de Belo Horizonte para o estudo de caso apóia-se nas seguintes razões. O estado de Minas Gerais, do qual Belo Horizonte é a capital, foi um dos pioneiros na formulaçãa e implementação de política ambiental no Brasil. O município de Belo Horizonte também está entre os pioneiros na institucionalização da política ambiental local no país. Belo Horizonte criou uma secretaria municipal para tratar especificamente do meio ambiente urbano no início dos anos 80 , articulando-a com instâncias de participação popular com poder decisório efetivo em meados dos anos 90, enquanto em outras capitais, como Rio de Janeiro e São Paulo, a criação das secretarias só se deu nos anos 90 e sua articulação com instâncias de participação no final da referida década. Além disso, as pesquisas que possibililitaram a construção dos índices foi realizada dentro de um programa financiado pela fundação de apoio à pesquisa do Estado de Minas Gerais.

\subsection{As Regiōes Metropolitanas de São Paulo e Belo Horizonte: semelhanças e diferenças}

As duas regiōes metropolitanas estudadas ocupam posições muito diferentes no contexto da sociedade e da economia brasileira.

Desde o início do século XX, a Região Metropolitana de São Paulo já se destacava como centro da principal atividade econômica do país, o café, e da 
Sustentabilidade e condiçôes de vida em áreas urbanas: medidas e determinantes em duas regiōes metropolitanas brasileiras

Tabela 1. Regiões Metropolitanas de São Paulo e Belo Horizonte, população dos núcleos centrais e dos municípios restantes (1970-2000).

\begin{tabular}{|c|c|c|c|c|}
\hline Regióes & 1970 & 1980 & 1991 & 2000 \\
\hline Total RMSP (1) & 8.113 .873 & 12.552 .203 & 15.395 .780 & 17.768 .135 \\
\hline São Paulo (2) & 5.924 .615 & 8.493 .226 & 9.646 .185 & 10.406 .166 \\
\hline Restante da RMSP (3) & 2.189 .258 & 4.058 .977 & 5.749 .595 & 7.361 .969 \\
\hline Total RMBH (4) & 1.619 .792 & 2.570 .281 & 3.385 .386 & 4.161 .028 \\
\hline Belo Horizonte (5) & 1.235 .030 & 1.780 .855 & 2.020 .161 & 2.229 .697 \\
\hline Restante da RMBH (6) & 384.762 & 789.426 & 1.365 .225 & 1.931 .331 \\
\hline (1) / (4) & 5,0 & 4,9 & 4,5 & 4,3 \\
\hline$(2) /(5)$ & 4,8 & 4,8 & 4,8 & 4,7 \\
\hline (3) / (6) & 5,7 & 5,1 & 4,2 & 3,8 \\
\hline
\end{tabular}

Fonte: IBGE (1970, 1980, 1991 e 2000).

Tabela 2. RMSP, tamanho da população e produto industrial segundo o tamanho dos municípios (2000).

\begin{tabular}{|l|c|c|c|c|}
\hline \multirow{2}{*}{$\begin{array}{c}\text { Tamanho dos municípios } \\
\text { segundo o No de habitantes }\end{array}$} & \multicolumn{2}{c|}{ População } & \multicolumn{2}{c|}{ Produto industrial } \\
\cline { 2 - 5 } & Absoluto & $\%$ & Absoluto & $\%$ \\
\hline São Paulo & $\mathbf{1 0 . 4 0 6 . 1 6 6}$ & $\mathbf{5 8 , 5 7}$ & $\mathbf{2 4 . 4 7 2 . 1 5 7}$ & $\mathbf{4 1 , 9 5}$ \\
\hline Guarulhos & 1.071 .299 & 6,03 & 5.493 .557 & 9,42 \\
\hline São Bernardo do Campo & 700.405 & 3,94 & 8.446 .131 & 14,48 \\
\hline Osasco & 650.993 & 3,66 & 1.247 .178 & 2,14 \\
\hline Santo Andre & 648.443 & 3,65 & 2.323 .889 & 3,98 \\
\hline Maua & 363.112 & 2,04 & 1.762 .580 & 3,02 \\
\hline Diadema & 356.389 & 2,01 & 2.481 .164 & 4,25 \\
\hline Carapicuíba & 343.668 & 1,93 & 127.350 & 0,22 \\
\hline Moji Das Cruzes & 329.680 & 1,86 & 695.290 & 1,19 \\
\hline Itaquaquecetuba & 272.416 & 1,53 & 302.278 & 0,52 \\
\hline Suzano & 228.439 & 1,29 & 1.845 .317 & 3,16 \\
\hline Barueri & 208.028 & 1,17 & 1.999 .652 & 3,43 \\
\hline Embu & 206.781 & 1,16 & 271.476 & 0,47 \\
\hline Total municípios > 200.000 & $\mathbf{1 5 . 7 8 5 . 8 1 9}$ & $\mathbf{8 8 , 8 4}$ & 51.468 .019 & $\mathbf{8 8 , 2 2}$ \\
\hline Municípios entre 100 e 200.000. & 1.264 .783 & 7,12 & 5.034 .236 & 8,63 \\
\hline Municípios < do que 100.000 & 717.533 & 4,04 & 1.840 .949 & 3,16 \\
\hline Total & $\mathbf{1 7 . 7 6 8 . 1 3 5}$ & $\mathbf{1 0 0 , 0 0}$ & $\mathbf{5 8 . 3 4 3 . 2 0 3}$ & $\mathbf{1 0 0 , 0 0}$ \\
\hline
\end{tabular}

Fonte: IBGE (1970, 1980, 1991 e 2000) e Fundação Seade (2002).

Tabela 3. RMBH, tamanho da população e produto industrial segundo o tamanho dos municípios (2000).

\begin{tabular}{|l|c|c|c|c|}
\hline \multirow{2}{*}{$\begin{array}{c}\text { Tamanho dos municípios } \\
\text { segundo o No de habitantes }\end{array}$} & \multicolumn{2}{c|}{ População } & \multicolumn{2}{c|}{ Produto industrial (r\$) } \\
\cline { 2 - 5 } & Absoluto & $\%$ & Absoluto & $\%$ \\
\hline Belo Horizonte & $\mathbf{2 . 2 2 9 . 6 9 7}$ & $\mathbf{5 3 , 5 9}$ & $\mathbf{6 . 4 4 6 . 3 4 0}$ & $\mathbf{4 6 , 1 5}$ \\
\hline Contagem & 536.408 & 12,89 & 2.115 .005 & 15,14 \\
\hline Betim & 303.588 & 7,30 & 3.179 .866 & 22,77 \\
\hline Ribeiráo das Neves & 246.589 & 5,93 & 150.257 & 1,08 \\
\hline Santa Luzia & 184.721 & 4,44 & 261.925 & 1,88 \\
\hline Ibirité & 132.843 & 3,19 & 156.094 & 1,12 \\
\hline Sabará & 114.557 & 2,75 & 156.968 & 1,12 \\
\hline Total municípios > 100.000 & 3.748 .403 & $\mathbf{9 0 , 0 8}$ & $\mathbf{1 2 . 4 6 6 . 4 5 3}$ & $\mathbf{8 9 , 2 6}$ \\
\hline Municípios entre 20 e 100.000 & 316.875 & 7,62 & 1.268 .117 & 9,08 \\
\hline Municípios <20.000 & 95.750 & 2,30 & 232.264 & 1,66 \\
\hline Total & $\mathbf{4 . 1 6 1 . 0 2 8}$ & $\mathbf{1 0 0 , 0 0}$ & $\mathbf{1 3 . 9 6 6 . 8 3 5}$ & $\mathbf{1 0 0 , 0 0}$ \\
\hline
\end{tabular}

Fonte: IBGE (1970, 1980, 1991 e 2000) e Fundação Seade (2002). 
Tabela 4. Regiōes metropolitanas de São Paulo e Belo Horizonte, taxas de crescimento geométricas anuais da população (1970-2000).

\begin{tabular}{|c|c|c|c|}
\hline Regióes & $1970 / 80$ & $1980 / 91$ & $1991 / 2000$ \\
\hline Total RMSP & 4,46 & 1,87 & 1,62 \\
\hline São Paulo & 3,67 & 1,16 & 0,85 \\
\hline Restante da RMSP & 6,37 & 3,22 & 2,81 \\
\hline Total RMBH & 4,73 & 2,54 & 2,34 \\
\hline Belo Horizonte & 3,73 & 1,15 & 1,11 \\
\hline Restante da RMBH & 7,45 & 5,11 & 3,97 \\
\hline
\end{tabular}

Fonte: IBGE (1970, 1980, 1991 e 2000).

sua emergente industrialização. Essa posição se consolidou com o amadurecimento do capitalismo brasileiro, na década de 50, quando a região se transformou no locus preferencial dos investimentos privados, nacionais e internacionais, e dos investimentos públicos. Apesar de um relativo processo de desconcentração industrial que se observa desde os anos 80, a hegemonia industrial da RMSP ainda se mantém até os dias atuais. A sua capacidade de atração populacional foi proporcional à sua relevância econômica, sendo assim, até os dias atuais, a região de maior atração demográfica do país.

A expansão econômica da RMBH por sua vez, se deu, de fato, somente após a segunda metade dos anos setenta, quando ela emerge como um pólo de convergência de investimentos na indústria automobilística e no setor metal-mecânico.

O resultado do desenvolvimento industrial nas duas regiōes metropolitanas pode ser verificado pela diferença entre os valores da produção industrial: em 2000 a produção industrial da RMSP ultrapassava os R $\$ 58$ bilhōes (Fundação Seade, 2001), mais de quatro vezes superior ao da RMBH, próximo dos $\mathrm{R} \$ 14$ bilhões (Fundação João Pinheiro, 2001).

Essas diferenças podem ser observadas, também em relação à população (Tabela 4). Apesar das diferenças diminuírem desde 1970, em 2000 a população da RMSP, com 17.768 milhões de habitantes, ainda era 4,3 vezes superior à da $\mathrm{RMBH}$, com 4.161 milhōes. Essas diferenças significativas podem, também, ser observadas entre as cidades de São Paulo e Belo Horizonte e entre os demais municípios das duas regiôes metropolitanas (Tabelas 2 e 3$)$.

Entretanto, se há uma nítida diferença entre as grandezas demográficas e econômicas das duas regiões, podem ser observadas algumas semelhanças importantes entre elas.

Tem havido, em ambas, uma enorme redução do ritmo do crescimento demográfico, principalmente nas capitais, mas não apenas nestas. A população de Belo Horizonte cresceu na última década a uma taxa anual de pouco mais de 1,0\% e São Paulo não alcançou $0,9 \%$ (Tabela 4 ). O crescimento dos outros municípios metropolitanos é bem maior, porém em nítido processo de retração. Essa redução do crescimento demográfico tem sido função do declínio generalizado das taxas de fecundidade no Brasil, mas, principalmente, pela diminuição dos fluxos migratórios.

Outro processo comum às duas regióes metropolitanas é o de inversão demográfica, pelo qual os municípios metropolitanos não centrais têm sido, cada vez mais, os grandes responsáveis pelo crescimento populacional das RMs. Nos anos 90,

Tabela 5. Regiões metropolitanas de São Paulo e Belo Horizonte, participação do núcleo e dos restantes dos municípios no crescimento populacional do total das regiôes (1970-2000).

\begin{tabular}{|l|c|c|c|}
\hline Regiōes & $\mathbf{1 9 7 0 / 8 0}$ & $\mathbf{1 9 8 0 / 9 1}$ & $\mathbf{1 9 9 1 / 2 0 0 0}$ \\
\hline São Paulo & 57,87 & 40,55 & 32,03 \\
\hline Restante da RMSP & 42,13 & 59,45 & 67,97 \\
\hline Belo Horizonte & 57,43 & 29,36 & 27,01 \\
\hline Restante da RMBH & 42,57 & 70,64 & 72,99 \\
\hline
\end{tabular}

Fonte: IBGE (1970, 1980, 1991 e 2000). 
eles deram conta de $68 \%$ do crescimento populacional da RMSP e de 73\% da RMBH (Tabela 5). Esse processo de inversão demográfica tem sido fortemente alimentado pelas migrações das capitais para os outros municípios metropolitanos em função não apenas da redistribuição espacial das atividades econômicas, mas, principalmente, das características excludentes do mercado imobiliário nos núcleos centrais, que expulsa boa parte da população mais pobre para os municípios vizinhos.

No que tange às características da rede urbana, existem diferenças substantivas entre as duas regióes. A RMSP possui um sistema urbano mais desenvolvido, com um número mais significativo de cidades de porte médio.

Contudo, apesar das diferenças de porte dos municípios, há semelhanças no que tange à forte concentração espacial da população. Na RMSP, quase $90 \%$ da população reside nos 13 (treze) municípios maiores que 200.000 habitantes e na RMBH, porcentagem semelhante mora nos 7 (sete) municípios maiores que 100.000 habitantes. O mesmo ocorre em relação à concentração econômica, estes mesmos municípios são responsáveis, nas duas regiōes, por aproximadamente $90 \%$ do PIB industrial. Somente as capitais, São Paulo e Belo Horizonte, em 2000 , geravam $42 \%$ e $46 \%$ do PIB industrial metropolitano, respectivamente.

Um grau tão elevado de concentração demográfica e econômica representa um desafio à gestão urbana e à busca da sustentabilidade em suas várias dimensōes. A concentração de população e das atividades econômicas e, conseqüentemente, das fontes poluidoras traz efeitos imediatos sobre a qualidade do ar e da água, além de representar uma pressão crescente sobre os recursos naturais e de comprometer a reprodução adequada do sistema ambiental micro-regional. Por outro lado, essa mesma concentração propicia sinergias políticas e sociais capazes de estimular uma melhor gestão e a adoção de medidas de promoção da sustentabilidade.

\subsection{O Sistema de Indices de Sustentabilidade Urbana: resultados para as regiōes metropolitanas de São Paulo e Belo Horizonte}

A metodologia acima descrita foi aplicada a 57 municípios, 36 da RMSP e 21 da RMBH, escolhidos a partir da definição de Aglomeração Metropolitana, segundo IPEA/IBGE/NESUR (1999). Antes de passar para a apresentação dos resultados propriamente dita cabe fazer duas observaçōes sobre o contexto no qual os resultados devem ser interpretados.

A primeira observação consiste em relembrar que os índices são uma medida relativa de desempenho e não uma medida absoluta. Isto é, que medem o desempenho relativo de cada município em relação aos extremos superiores e inferiores de desempenho no conjunto de municípios para os quais os índices foram calculados. Portanto, um hipotético município com pontuação 1 no índice de qualidade ambiental, por exemplo, ainda poderia aprimorar seu desempenho, e assim elevar o nível geral de desempenho do conjunto de municípios, essa pontuação não significa, em absoluto, que ele possui uma qualidade ambiental perfeita.

A segunda observação diz respeito às limitaçōes referentes ao escopo temporal utilizado na construção dos índices, que foram calculados para um único ano-base. A utilização de séries temporais permitiria

Tabela 6. Média dos índices temáticos por classe de tamanho, RMSP e RMBH (2000).

\begin{tabular}{|l|l|l|c|}
\hline Município central & IQA & ICP & IDHM \\
\hline RMSP São Paulo (capital) & 0,47 & 0,97 & 0,84 \\
\hline RMBH Belo Horizonte (capital) & 0,50 & 0,95 & 0,84 \\
\hline Municípios de porte médio & & & \\
\hline RMSP Municípios > 200 mil & 0,56 & 0,27 & 0,80 \\
\hline RMSP Municípios entre 100 e 200 mil & 0,58 & 0,18 & 0,80 \\
\hline RMBH Municípios > $100 \mathrm{mil}$ & 0,59 & 0,31 & 0,76 \\
\hline Municípios pequenos & & & 0,18 \\
\hline RMSP Municípios < $100 \mathrm{mil}$ & 0,56 & 0,27 \\
\hline RMBH Municípios entre 20 e $100 \mathrm{mil}$ & 0,50 & 0,18 & 0,75 \\
\hline RMBH Municípios < $20 \mathrm{mil}$ & 0,53 & \\
\hline
\end{tabular}

Fonte: elaboração própria. 
comparações mais refinadas entre os índices. Entretanto a construção de índices para anos-base anteriores demandaria a utilização de dados primários, o que poderá ser incorporada em trabalhos futuros.

Os resultados obtidos estão apresentados através das médias dos índices de Qualidade Ambiental (IQA), Capacidade Sócio-Política (ICP) e Desenvolvimento Humano Municipal (IDHM), para as duas Regiōes Metropolitanas, segundo os seus núcleos e os demais municípios agrupados segundo classes de tamanho. As classes de tamanho para as regiōes metropolitanas de Belo Horizonte e
São Paulo são ligeiramente diferentes, uma vez que devido à diferença de composição das mesmas, para a primeira foi necessário dividir os municípios pequenos em dois grupos e para a segunda foi necessário dividir os municípios de porte médio em dois grupos, de modo a tornar explícitas diferenças importantes.

As capitais, Belo Horizonte e São Paulo, apresentaram IQA menor ou igual à média dos demais municípios agrupados e o IDHM sensivelmente maior. Entretanto, é em relação ao ICP que as duas capitais se destacam sensivelmente

Tabela 7. Índices temáticos e VA industrial municipal, RMSP (2000).

\begin{tabular}{|c|c|c|c|c|}
\hline Município & IQA & ICP & IDHM & $\begin{array}{c}\text { VA industrial } \\
(\mathrm{R} \$ 1.000 \text { de } 2000)\end{array}$ \\
\hline Sao Paulo & 0,47 & 0,97 & 0,84 & 24.472 .157 \\
\hline & \multicolumn{3}{|c|}{ Municípios > $200 \mathrm{mil}$} & \\
\hline Guarulhos & 0,55 & 0,30 & 0,80 & 5.493 .557 \\
\hline Sao Bernardo do Campo & 0,50 & 0,28 & 0,83 & 8.446 .131 \\
\hline Osasco & 0,52 & 0,18 & 0,82 & 1.247 .178 \\
\hline Mauá & 0,58 & 0,27 & 0,78 & 1.762 .580 \\
\hline Diadema & 0,54 & 0,33 & 0,79 & 2.481 .164 \\
\hline Carapicuiba & 0,57 & 0,18 & 0,79 & 127.350 \\
\hline Moji das Cruzes & 0,66 & 0,32 & 0,80 & 695.290 \\
\hline Itaquaquecetuba & 0,63 & 0,20 & 0,74 & 302.278 \\
\hline Embu & \multicolumn{3}{|c|}{ Municípios entre 100 e 200 mil } & \\
\hline Taboao da Serra & 0,60 & 0,18 & 0,81 & 1.187 .101 \\
\hline Itapevi & 0,61 & 0,15 & 0,76 & 235.218 \\
\hline Cotia & 0,56 & 0,26 & 0,83 & 737.017 \\
\hline Ferraz de Vasconcelos & 0,64 & 0,14 & 0,77 & 164.121 \\
\hline Sao Caetano do Sul & 0,50 & 0,21 & 0,92 & 1.698 .602 \\
\hline Francisco Morato & 0,54 & 0,11 & 0,74 & 2.570 \\
\hline Itapecerica da Serra & 0,59 & 0,21 & 0,78 & 606.453 \\
\hline Franco da Rocha & 0,59 & 0,21 & 0,78 & 138.500 \\
\hline Ribeirao Pires & 0,61 & 0,19 & 0,81 & 264.654 \\
\hline Aruja & 0,47 & 0,20 & 0,79 & 192.001 \\
\hline Embu-Guacu & 0,61 & 0,12 & 0,77 & 120.105 \\
\hline Cajamar & 0,55 & 0,18 & 0,79 & 507.033 \\
\hline Santa Isabel & 0,56 & 0,30 & 0,77 & 74.506 \\
\hline Rio Grande da Serra & 0,55 & 0,03 & 0,76 & 13.779 \\
\hline Vargem Grande Paulista & 0,48 & 0,17 & 0,80 & 102.998 \\
\hline Guararema & 0,58 & 0,14 & 0,80 & 26.735 \\
\hline Pirapora do Bom Jesus & 0,47 & 0,09 & 0,77 & 32.887 \\
\hline Sao Lourenco da Serra & 0,65 & 0,16 & 0,77 & 3.708 \\
\hline
\end{tabular}

Fonte: elaboração própria. 
dos demais municípios, com índices significativamente superiores, resultado consistente com sua capacidade de polarização e centralização do poder e com o maior desenvolvimento e robustezes institucionais decorrentes, próprios das capitais dos estados.

Em ambas as regiōes metropolitanas, o IQA para as cidades de porte médio (com mais de $100 \mathrm{mil}$ habitantes), tende a ser ligeiramente superior ao obtido tanto pelas cidades de menor porte quanto pelas capitais. O IDHM apresenta-se ligeiramente superior para os municípios de maior porte demográfico, em ambas as regióes metropolitanas.

Incorporando à análise o valor da produção industrial, observa-se, no caso específico da RMSP, para os municípios com mais de 200 mil habitantes, as diferenças entre o IQA e o IDHM tendem a ser maior nos municípios onde há uma maior industrialização. Um caso interessante é o de Santo André, que apresenta o IQA mais baixo e os ICP e IDHM mais altos dentre os municípios desse grupo. Ouros dois casos interessante são os de
Guarulhos e Moji das Cruzes, que apresentam situação mais equilibrada, com menores distâncias entre o IQA e o IDHM. Estes resultados sugerem que o trade-off entre o IQA e o IDHM, rejeitado para o conjunto das duas regióes metropolitanas conforme discussão no item 4, seja uma possibilidade no caso específico dos municípios fortemente industrializados.

Nos municípios entre 100 e 200.000 habitantes, na RMSP, a distância entre o IQA e o IDHM tende a ser significativamente menor do que aquela verificada no grupo imediatamente superior. A grande exceção é São Caetano do Sul, com o maior IDHM e a segunda maior distância entre IQA e IDHM da região metropolitana, apresentando também ICP ligeiramente superior ao apresentado pelos demais municípios de sua classe de tamanho. Note-se que esse município, apesar de ter uma população de apenas 140 mil habitantes, se situa em nono lugar entre os mais industrializados.

Para os municípios com menos de 100.000 habitantes, pequenos e com um valor da produção

Tabela 8. Índices temáticos e PIB industrial municipal, RMBH (2000).

\begin{tabular}{|c|c|c|c|c|}
\hline Município & IQA & ICP & IDHM & $\begin{array}{l}\text { PIB industrial } \\
(\mathrm{R} \$ 1.000,00 \\
\text { de } 2000)\end{array}$ \\
\hline Belo Horizonte & 0,50 & 0,95 & 0,84 & 6.446 .340 \\
\hline & & Municípios > $100 \mathrm{mil}$ & & \\
\hline Contagem & 0,53 & 0,50 & 0,79 & 2.115 .005 \\
\hline Betim & 0,62 & 0,43 & 0,78 & 3.179 .866 \\
\hline Ribeirao das Neves & 0,54 & 0,12 & 0,75 & 150.257 \\
\hline Santa Luzia & 0,62 & 0,20 & 0,75 & 261.925 \\
\hline Ibirite & 0,62 & 0,25 & 0,73 & 156.094 \\
\hline Sabara & 0,61 & 0,35 & 0,77 & 156.968 \\
\hline \multicolumn{5}{|c|}{ Municípios entre 20 e $100 \mathrm{mil}$} \\
\hline Vespasiano & 0,36 & 0,31 & 0,75 & 367.874 \\
\hline Nova Lima & 0,57 & 0,32 & 0,82 & 411.824 \\
\hline Pedro Leopoldo & 0,38 & 0,30 & 0,81 & 282.459 \\
\hline Lagoa Santa & 0,36 & 0,40 & 0,78 & 110.223 \\
\hline Caete & 0,72 & 0,16 & 0,79 & 18.920 \\
\hline Igarape & 0,52 & 0,36 & 0,75 & 38.925 \\
\hline Mateus Leme & 0,60 & 0,05 & 0,71 & 37.893 \\
\hline \multicolumn{5}{|c|}{ Municípios $<20 \mathrm{mil}$} \\
\hline Sao Joaquim de Bicas & 0,50 & 0,21 & 0,75 & 24.866 \\
\hline Sarzedo & 0,58 & 0,17 & 0,75 & 37.507 \\
\hline Juatuba & 0,54 & 0,18 & 0,75 & 59.426 \\
\hline Sao Jose da Lapa & 0,45 & 0,25 & 0,71 & 83.876 \\
\hline Raposos & 0,61 & 0,23 & 0,76 & 17.407 \\
\hline Mario Campos & 0,53 & 0,09 & 0,75 & 6.824 \\
\hline Confins & 0,50 & 0,13 & 0,77 & 2.359 \\
\hline
\end{tabular}

Fonte: elaboração própria. 
industrial relativamente industrial inexpressivo, não se observa uma regularidade nas distâncias entre o IQA e o IDHM.

Os municípios da Região Metropolitana de $\mathrm{BH}$ apresentam, em geral, menor distância entre IQA e IDHM do que os municípios paulistas analisados. Tal característica é válida, principalmente, para os municípios com mais de 100.000 habitantes, com a exceção de Contagem. Aqueles com população entre 100 e 500 mil apresentam uma maior incidência de IQA alto, quatro dos seis maiores índices da $\mathrm{RMBH}$, uma surpresa devido à pobreza generalizada desses municípios, que servem de alternativa de moradia de baixo custo no entorno da capital mineira, pouco refletida no IDHM. A exceção clara é Betim, que possui o segundo produto industrial da região $\mathrm{e}$ também apresenta alto IQA e pequena distância entre IQA e IDHM.

Embora a capacidade político institucional se apresente sensivelmente superior em Belo Horizonte, outros dois municípios, Contagem e Betim, destacam-se significativamente dos demais, fenômeno para o qual não há paralelo na RMSP.

Dentre os municípios com população entre $20 \mathrm{e}$ 100.000 habitantes, os quais não apresentam uma regularidade expressiva, vale a pena chamar atenção para Nova Lima com IDHMM de 0,82 e Caeté com IQA de 0,72. Ambos são municípios mais antigos, de tradição mineradora, e que hoje servem como alternativa para a expansão imobiliária da classe média de BH. O alto valor de IQA encontrado para Caeté explica-se pela existência no município de uma importante área de preservação ambiental o que resulta em uma cobertura vegetal bastante superior à média da região metropolitana.

Os mapas temáticos abaixo espacializam os resultados dos índices de qualidade ambiental e desenvolvimento humano municipal para todos os municípios das duas regiōes metropolitanas.

\section{Sustentabilidade e condições de vida nas regióes metropolitanas de São Paulo e Belo Horizonte}

Para melhor caracterizar a sustentabilidade nas regiōes metropolitanas, em suas diferentes dimensões, elas foram devidamente comparadas através do barômetro de Prescott-Allen, assim como através de testes estatísticos de correlação entre os três índices temáticos e deles com os indicadores econômicos e populacionais tradicionais.

As relações entre as dimensões ambiental e humana da sustentabilidade foram exploradas a partir da construção do barômetro de sustentabilidade inspirado na metodologia criada por Prescott-Allen (1995). Ele consiste na plotagem de índices ou indicadores em dois eixos, o primeiro representando o sistema humano e o segundo o sistema natural. No barômetro aqui construído o IDHM compõe o eixo do sistema humano e o IQA compõe o eixo do sistema ambiental.

Para determinar os intervalos de qualidade dos dois índices, foram calculados os quartis da distribuição dos seus valores para cada regiāo metropolitana. Aqueles situados no primeiro quartil foram considerados de baixa qualidade ambiental, no segundo quartil como razoável, no terceiro quartil como boa, e no último quartil como de alta qualidade ambiental.

O IQA foi então plotado no eixo vertical e o IDHM no eixo horizontal em ordem decrescente e os dezesseis quadrantes resultantes foram então classificados em quatro situações distintas: sustentável, potencialmente sustentável, potencialmente insustentável e sustentável. Situações consideradas sustentáveis são aquelas que apresentam ambos indicadores altos; as potencialmente sustentáveis combinam bons e altos indicadores; as potencialmente insustentáveis apresentam pelo menos um dos indicadores baixo ou razoável e as insustentáveis apresentam pelo menos um dos indicadores muito baixo ou baixo.

O objetivo desta análise é tornar mais explícita e permitar uma discussão mais aprofundada das situações de equilíbrio e das situações de trade-offentre qualidade ambiental e desenvolvimento humano. As situaçôes onde há um trade-off, uma alta qualidade ambiental vem acompanhada de um baixo desenvolvimento humano e vice-versa, foram consideradas insustentáveis. Também foram consideradas insustentáveis situaçōes de equilíbrio negativo, isto é, baixa qualidade ambiental e baixo desenvolvimento humano. Foram consideradas como sustentáveis situaçôes de equilíbrio positivo. Cabe ressaltar mais 
Sustentabilidade e condiçôes de vida em áreas urbanas: medidas e determinantes em duas regiōes metropolitanas brasileiras

Mapas 1-4. Índices de qualidade ambiental e desenvolvimento humano municipal para todos os municípios das duas regiōes metropolitanas.
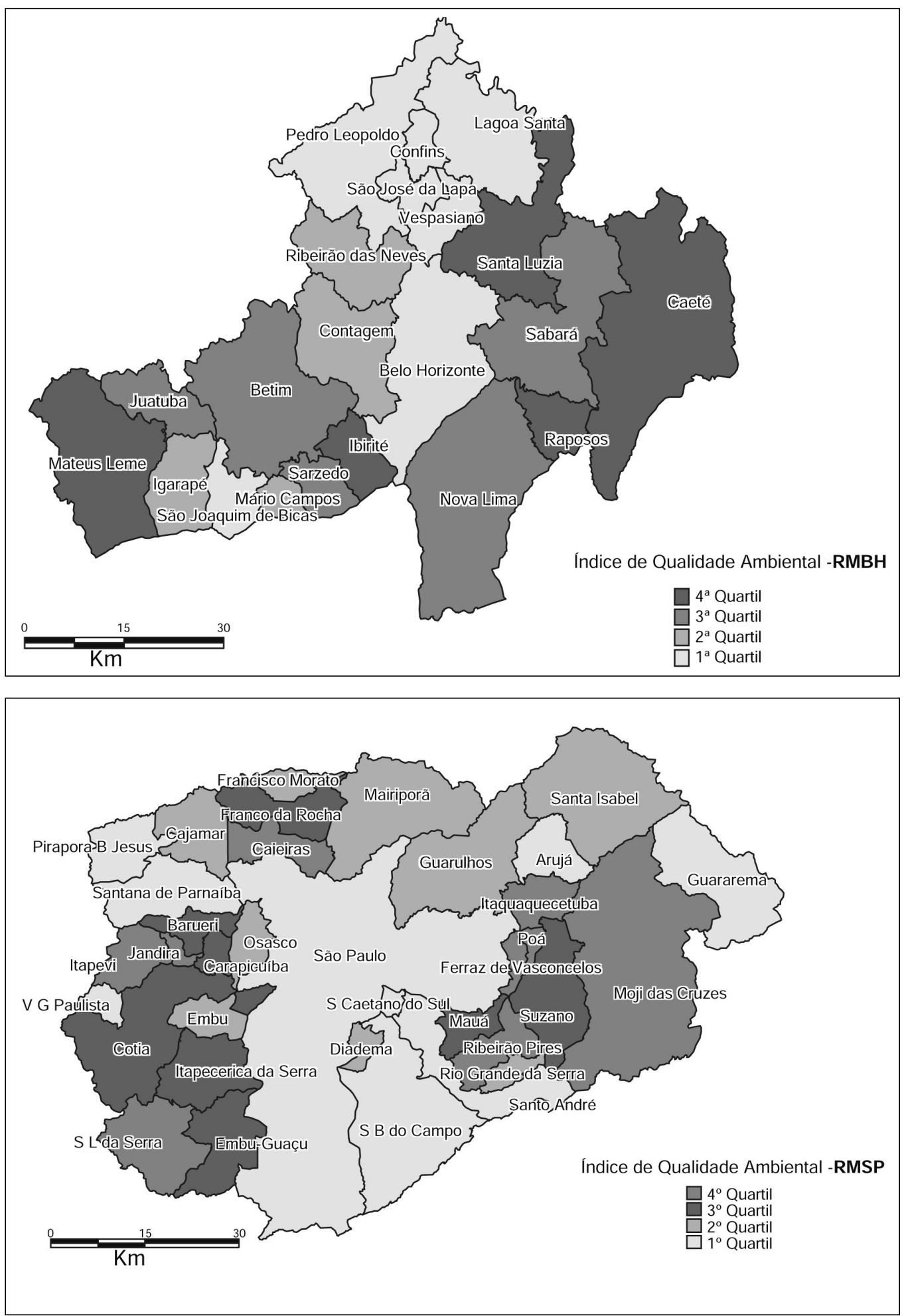
Tánia Moreira Braga
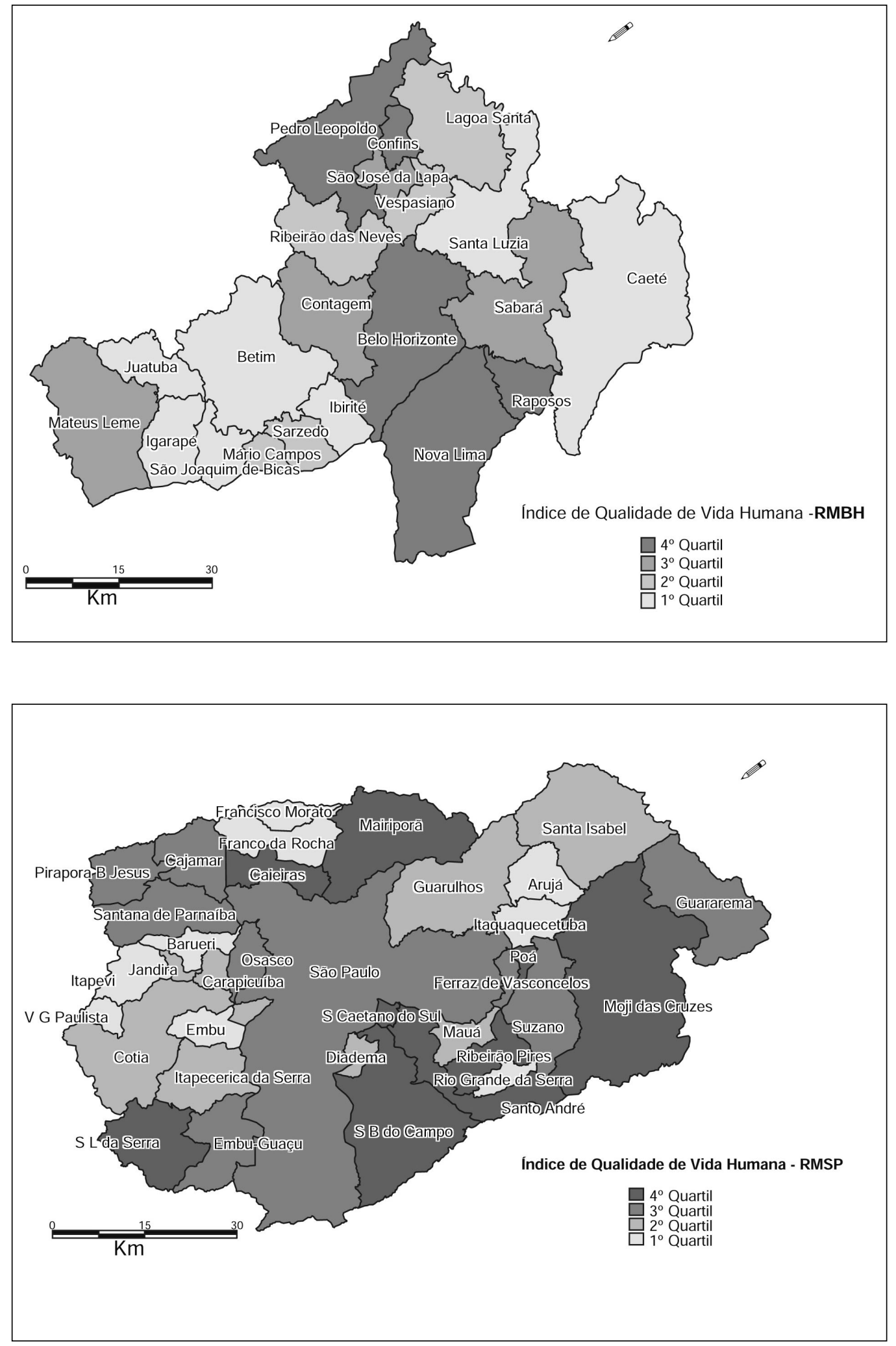
Sustentabilidade e condiçōes de vida em áreas urbanas: medidas e determinantes em duas regiōes metropolitanas brasileiras

Tabela 9. Barômetro de sustentabilidade RMSP.

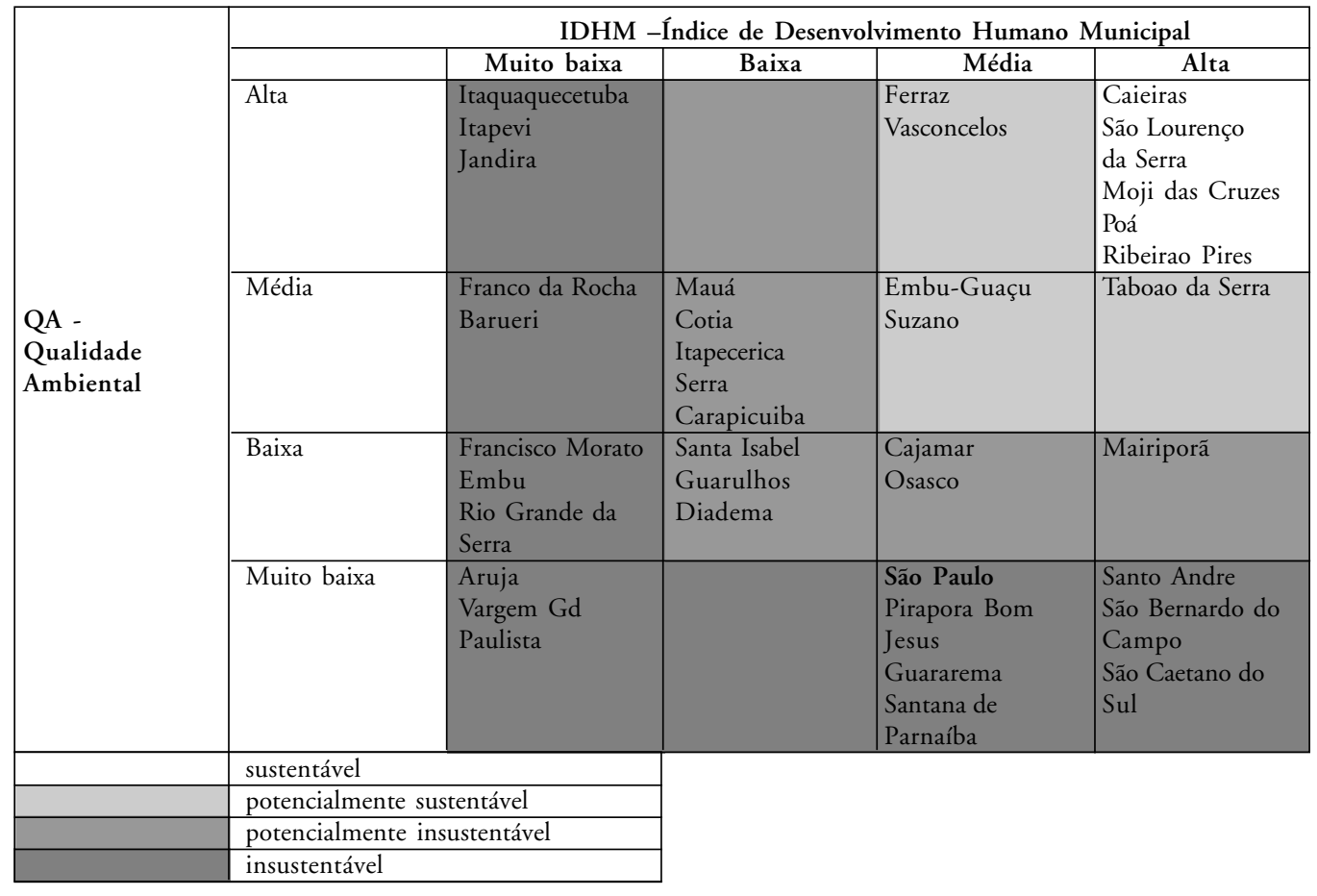

Barômetro de Sustentabilidade RMBH.

\begin{tabular}{|c|c|c|c|c|c|}
\hline & \multicolumn{5}{|c|}{ IDHM -Índice de Desenvolvimento Humano Municipal } \\
\hline & & Muito baixa & Baixa & Média & Alta \\
\hline & Alta & $\begin{array}{l}\text { Caete } \\
\text { Santa Luzia } \\
\text { Ibirité }\end{array}$ & & Mateus Leme & Raposos \\
\hline & Média & $\begin{array}{l}\text { Betim } \\
\text { Juatuba }\end{array}$ & Sarzedo & Sabara & Nova Lima \\
\hline & Baixa & Igarape & $\begin{array}{l}\text { Ribeirao das } \\
\text { Neves } \\
\text { Diadema } \\
\text { Mario Campos }\end{array}$ & Contagem & $\begin{array}{l}\text { Mairiporã } \\
\text { Osasco }\end{array}$ \\
\hline & Muito baixa & $\begin{array}{l}\text { S Joaquim de } \\
\text { Bicas }\end{array}$ & $\begin{array}{l}\text { Vespasiano } \\
\text { Lagoa Santa }\end{array}$ & São Jose da Lapa & $\begin{array}{l}\text { Belo Horizonte } \\
\text { Confins } \\
\text { Pedro Leopoldo }\end{array}$ \\
\hline \multirow{4}{*}{\begin{tabular}{|l} 
\\
\\
QA - \\
Qualidade \\
Ambiental
\end{tabular}} & \multicolumn{2}{|l|}{ sustentável } & & & \\
\hline & \multicolumn{2}{|c|}{ potencialmente sustentável } & & & \\
\hline & \multirow{2}{*}{\multicolumn{2}{|c|}{ potencialmente insustentável }} & & & \\
\hline & & & & & \\
\hline
\end{tabular}


uma vez, que as quatro situações são comparativas dentro do conjunto dos municípios estudados, e não situações de sustentabilidade derivadas da comparação com valores de referência ou benchmarks.

São Paulo e Belo Horizonte, as capitais, foram classificadas como insustentáveis. Na RMSP, cinco municípios foram classificados como sustentáveis, e na RMBH apenas um município recebeu tal classificação. Os municípios industriais da RMSP, em sua maioria, foram classificados como insustentáveis, com a exceção de Diadema, Osasco e Guarulhos, classificados como potencialmente insustentáveis e Suzano como potencialmente sustentável. Na RMBH, Betim e Contagem, os dois municípios industriais, foram classificados como insustentável e potencialmente insustentável, respectivamente.

É interessante observar, também, no que se refere às situaçōes de equilíbrio, doze municípios da RMSP e cinco da RMBH apresentam a mesma classificação nos dois índices. Foram encontrados três municípios na pior situação de equilíbrio, qualidade ambiental baixa e desenvolvimento humano muito baixo.

No melhor equilíbrio, ou seja, alta qualidade ambiental e alto desenvolvimento humano encontram-se um município da RMBH e cinco municípios da RMSP. Raposos na RMBH e Caieiras, São Lourenço da Serra e Poá na RMSP são demograficamente pequenos e de atividade industrial inexpressiva. Ribeirão Pires é um município médio, entre 100 e 200 mil habitantes, com uma atividade industrial inexpressiva. Moji das Cruzes possui população acima de 200 mil e atividade industrial relevante.

As situações de grande desequilíbrio, combinando situações opostas de qualidade ambiental e desenvolvimento humano, são também bastante sugestivas. Com qualidade ambiental muito baixa e alto desenvolvimento humano, se situam Belo Ho- rizonte, Confins e Pedro Leopoldo na RMBH e Santo André, São Bernardo do Campo e São Caetano do Sul na RMSP. Na situação assimétrica oposta, alta qualidade ambiental e desenvolvimento humano muito baixo, foram encontrados três municípios em cada uma das regiōes metropolitanas.

A comparação dos índices temáticos entre si através de testes de correlação traz resultados bastante interessantes.

A fraquíssima correlação encontrada entre o IDHM e o IQA afastam a hipótese de um trade-off recorrente entre desenvolvimento humano e qualidade ambiental nos municípios estudados. Já a correlação positiva significativa entre o ICP e o IDHM são um bom indicador de que na região estudada o desenvolvimento humano e a capacidade institucional caminham lado a lado.

A existência de uma correlação negativa encontrada entre o IQA e o ICP, ainda que baixa, é surpreendente, uma vez que se esperava tendo por base a literatura uma correlação positiva entre qualidade ambiental e fortalecimento institucional. Ou seja, esperava-se que municípios mais fortes institucionalmente possuíssem sinergias políticas capazes de estimular uma adoção de medidas de promoção da sustentabilidade que se refletissem no índice ambiental. Esta surpresa é reforçada pelos resultados das capitais, Belo Horizonte e São Paulo, classificadas como insustentáveis na análise do barômetro e detentoras dos indicadores de capacidade política sensivelmente superiores aos demais. Cabe portanto, levantar aqui uma série de questôes sobre o significado desse resultado. A correlação negativa estaria indicando uma falha grave nos mecanismos de governança? Ou tal resultado poderia ser atribuído a outros fatores? Levantamos aqui a hipótese de que esta correlação negativa espelha possivelmente um gap temporal entre os esforços empreendidos na gestão e os resultados efetivos em

Tabela 10. Correlações entre índices temáticos.

\begin{tabular}{|l|c|c|c|}
\hline & IQA & ICP & IDHM \\
\hline IQA & 1 & $-\mathbf{0 , 2 8}$ & $-0,14$ \\
\hline ICP & $-0,28$ & 1 & $\mathbf{0 , 3 8}$ \\
\hline IDHM & $-0,14$ & $\mathbf{0 , 3 8}$ & 1 \\
\hline
\end{tabular}

Fonte: elaboração própria. Nota. Números em negrito: correlação significativa ao nivel 0,01 (2-tailed). Números em itálico e negrito: correlação significativa ao nível 0,05 (2-tailed). 
relação à qualidade ambiental. Ou seja, os resultados presentes positivos nos indicadores de capacidade institucional irão se refletir em melhorias na qualidade ambiental futuras de médio e longo prazo. Visto que os sistemas ambientais precisam de tempo para se recuperar, os resultados de ações presentes para melhoria da qualidade dos recursos hídricos e ampliação da cobertura vegetal, por exemplo, seriam visíveis apenas no futuro. Tal hipóse somente poderá ser comprovada em estudos futuros. Comprovar tal hipótese através da construção de ambos os índices para ano-base na década anterior é uma possibilidade interessante que também poderá ser adotada em versões futuras do sistema de índices de sustentabilidade urbana.

A literatura recente sobre o tema sustentabilidade aponta para correlações diversas e por vezes opostas entre os fenômenos qualidade ambiental e desenvolvimento econômico. Parte da literatura aponta para uma relação direta entre os fenômenos, indicando que a qualidade ambiental se beneficia do desenvolvimento econômico. Uma segunda corrente sustenta a existência de uma relação inversa, um trade-off, refletindo uma supremacia das externalidades negativas sobre as positivas. Uma terceira corrente aponta para a existência de uma relação que pode ser descrita por uma curva em $U$ invertido, denominada curva de Kuznets. A primeira metade da curva de Kuznets indica que em níveis baixos e médios de desenvolvimento econômico haveria uma relação inversa entre qualidade ambiental e desenvolvimento econômico, ou seja, à medida que um país ou cidade fosse se desenvolvendo econômicamente iriam aparecendo externalidades ambientais negativas que implicariam em altos níveis de degradação e baixa qualidade ambiental. A segunda metade da curva de Kuznets indica que em níveis médios e altos de desenvolvimento econômico a relação inversa seria substituída por uma relação direta, na qual à medida que o desenvolvimento econômico prossegue e se reforça as externalidades positivas iriam se tornar mais importantes que as negativas, implicando em melhorias da qualidade ambiental e reversão do processo de degradação. Cabe atentar entretanto para o perigo de leituras maniqueístas da terceira corrente sugerirem serem válidas estrategias do tipo "crescer para depois limpar". (Environmental Sustainability Index, 2002; Esty e Porter, 2002; Dasgupta et al., 1995).

Os indicadores econômicos utilizados na comparação com os índices de sustentabilidade urbana foram o PIB industrial, ou o valor da produção industrial, e a renda per capta familiar, com o objetivo de captar as diferenças entre o grau de industrialização e a riqueza relativa apropriada pela população. Adotamos o PIB industrial, e não o PIB municipal, com o objetivo de investigar se o trade-off entre grau de industrialização e o índice de qualidade ambiental, sujerido pela verificação de um grande afastamento entre os valores do IDHM e do IQA no caso específico dos municípios com alto grau de industrialização, seria ou não verificável para o conjunto de municípios como um todo.

No que se refere à relação com os indicadores demográficos, utilizou-se a população urbana e a densidade urbana (população urbana sobre área do perímetro urbano), considerados pela literatura como importantes indutores de sustentabilidade (McGranahan e Satterthwaite, 2002; Environmental Sustainability Index, 2002; Miller e Small, 2003).

Ambos indicadores econômicos possuem uma expressiva correlação positiva com o ICP e com o IDHM. A renda per capta familiar média apresentou uma correlação pouco relevante com a qualidade ambiental, com sinal negativo, e uma alta e positiva com o IDHM.

Tabela 11. Correlações entre índices temáticos e indicadores econômicos/demográficos.

\begin{tabular}{|l|c|c|c|}
\hline & IQA & ICP & IDHM \\
\hline PIB/VAF industrial & $-0,19$ & $\mathbf{0 , 7 3}$ & $\mathbf{0 , 3 6}$ \\
\hline Renda per capta familiar média & $-\mathbf{0 , 2 5}$ & $\mathbf{0 , 4 3}$ & $\mathbf{0 , 8 9}$ \\
\hline População urbana & $-0,16$ & $\mathbf{0 , 7 2}$ & $\mathbf{0 , 2 8}$ \\
\hline Densidade populacional urbana & 0,04 & $\mathbf{0 , 2 5}$ & $\mathbf{0 , 4 3}$ \\
\hline
\end{tabular}

Fonte: elaboração própria.

Nota. Números em negrito: correlação significativa ao nivel 0,01 (2-tailed). Números em itálico e negrito: correlação significativa ao nível 0,05 (2-tailed) 
Tabela 12. Correlações entre indicadores componentes do IQA e ICP e indicadores econômicos/demográficos.

\begin{tabular}{|l|l|l|c|c|c|c|}
\hline \multicolumn{1}{|c|}{ Indicador } & \multicolumn{1}{|c|}{$\begin{array}{c}\text { Tipo de } \\
\text { indicador }\end{array}$} & $\begin{array}{c}\text { Abrangência } \\
\text { espacial }\end{array}$ & $\begin{array}{c}\text { PIB/VAF } \\
\text { industrial }\end{array}$ & $\begin{array}{c}\text { Renda per } \\
\text { capta } \\
\text { familiar } \\
\text { média }\end{array}$ & $\begin{array}{c}\text { População } \\
\text { urbana }\end{array}$ & $\begin{array}{c}\text { Densidade } \\
\text { populacional } \\
\text { urbana }\end{array}$ \\
\hline Gestão pública municipal & Resposta & Municipal & 0,47 & 0,37 & 0,41 & 0,3 \\
\hline Redução da pressão veicular & Pressão & Global & $-0,59$ & $-0,79$ & $-0,49$ & $-0,24$ \\
\hline $\begin{array}{l}\text { Autonomia política } \\
\text { administrativa }\end{array}$ & Resposta & Municipal & 0,66 & 0,69 & 0,65 & 0,21 \\
\hline $\begin{array}{l}\text { Redução da pressão } \\
\text { domiciliar }\end{array}$ & Pressão & Intra-Urbano & 0,4 & 0,69 & 0,33 & 0,18 \\
\hline Serviços sanitários & Estado & Intra-Urbano & 0,33 & 0,4 & 0,25 & 0,62 \\
\hline Gestão ambiental & Resposta & Municipal & 0,71 & 0,22 & 0,72 & 0,26 \\
\hline $\begin{array}{l}\text { Informação e participação } \\
\text { política }\end{array}$ & Resposta & Municipal & 0,75 & 0,23 & 0,81 & 0,13 \\
\hline Qualidade da habitação & Estado & Intra-Urbano & $-0,36$ & $-0,09$ & $-0,22$ & $-0,51$ \\
\hline $\begin{array}{l}\text { Redução da pressão } \\
\text { do consumo }\end{array}$ & Pressão & Regional & $-0,3$ & $-0,83$ & $-0,25$ & $-0,23$ \\
\hline Cobertura vegetal & Estado & Regional & $-0,1$ & $-0,2$ & $-0,09$ & $-0,28$ \\
\hline Qualidade recursos hídricos & Estado & Regional & 0,05 & $-0,26$ & $-0,05$ & $-0,2$ \\
\hline $\begin{array}{l}\text { Redução da pressão } \\
\text { industrial }\end{array}$ & Pressão & Regional & 0,17 & 0,13 & 0,13 & 0,26 \\
\hline
\end{tabular}

Nota. Números em negrito: correlação significativa ao nivel 0,01 (2-tailed). Números em itálico e negrito: correlação significativa ao nível 0,05 (2-tailed).

O grau de industrialização não pode ser considerado, isoladamente, como um indutor da sustentabilidade urbana. Apesar de ser um indutor direto da capacidade político institucional, sua influência sobre o desenvolvimento humano é menos determinante, assim como sobre a qualidade ambiental. Desta forma, rejeitou-se a hipótese de que o trade-off entre industrialização e qualidade ambiental fosse válido para o conjunto de municípios.

Por outro lado a renda per capta familiar média, que pode ser considerada um indutor direto do desenvolvimento humano, possui correlação positiva com a capacidade político institucional e correlação negativa com a qualidade ambiental, não podendo também ser considerada, isoladamente, como um indutor da sustentabilidade urbana.

Verifica-se uma correlação positiva significativa entre os índices de capacidade político-institucional e o tamanho da população urbana, fortemente influenciada pelas populações das capitais das duas regiōes metropolitanas. Não foi encontrada nenhuma correlação entre o índice de qualidade ambiental e os indicadores demográficos, eliminando-se assim a hipótese de que cidades maiores são aquelas que apresentam necessariamente pior qualidade ambiental.
A tabela 11 apresenta os resultados de análise semelhante realizada para cada um dos 12 indicadores que compõem os índices de qualidade ambiental e capacidade político-institucional. Para efeitos de análise agrupamos em indicadores segundo seu tipo -estado, resposta, pressão- e segundo sua abrangência geo-espacial-global, regional, municipal, intra-urbano.

Embora existam diferenças entre os resultados apresentados individualmente, pode-se discernir um claro padrão para as cidades estudadas, no qual os indicadores de resultado apresentam correlaçōes mais fortes com os indicadores econômicos, seguidos pelos indicadores de pressão. Já os indicadores de estado apresentaram fraca relação com os indicadores econômicos. Em um segundo padrão, pode ser observado que todos os indicadores intra-urbanos, municipais e de impacto global, se correlacionavam com as medidas econômicas, enquanto a maior parte dos indicadores de impacto regional não apresentaram correlação significativa com os indicadores econômicos.

Ao examinar as correlações com os indicadores demográficos, pode-se constatar que os indicadores de resultado apresentaram novamente as correlações mais fortes. Entretanto, de forma distinta da relação com os indicadores econômicos, a estes seguem os 
indicadores de estado que apresentaram correlação significativa com a densidade populacional. Dentre os indicadores de pressão, apenas um, a redução da pressão veicular, apresentou correlação significativa com o indicador população urbana. Tais resultados indicam que os efeitos relacionados ao tamanho das cidades são refletidos pelos indicadores de pressão e resposta, ao passo que os efeitos da maior ou menor densidade populacional estão refletidos nos indicadores de estado.

Os indicadores municipais possuem correlação significativa com as medidas populacionais. Ao passo que alguns indicadores de impacto global e intraurbano apresentaram correlaçôes interessantes com a densidade demográfica, os indicadores de impacto regional não apresentaram relação expressiva com os indicadores demográficos.

\section{Considerações finais}

O sistema de índices de sustentabilidade aqui apresentado é um projeto piloto, ainda aberto a novas construções e (des)construções.

A cálculo dos índices para os municípios das regiōes metropolitanas de São Paulo e Belo Horizonte foi realizada em menos de seis meses, com recursos e equipe limitados. Ainda assim, os resultados se mostraram consistentes, o que demonstra ser possível a construção de índices temáticos e indicadores compreensivos de sustentabilidade urbana, imprescindíveis para que se possa fazer deste um conceito mais operacional e mensurável.

O ponto forte do SISU é sua possibilidade de utilização como ferramenta de monitoramento dos esforços na promoção da sustentabilidade urbana. Tal ferramenta é uma base racional eficaz para priorizar esforços e direcionar políticas públicas.

Os resultados obtidos indicam claramente os municípios de maior e menor sucesso relativo em cada uma das três dimensões consideradas da sustentabilidade. Moji das Cruzes e Ribeirão Pires na RMSP e Raposos, Nova Lima e Sabará na RMBH são exemplos de municípios que vem trilhando um caminho mais sustentável e podem trazer luzes interessantes sobre como atingir maior equilíbrio entre qualidade ambiental e desenvolvimento humano. Arujá e Vargem Grande Paulista na RMSP e
São Joaquim de Bicas na RMBH são exemplos opostos, de uma clara e extrema fragilidade, ambiental, sócio-econômica e político-institucional, demandando atenção especial e ações urgentes.

Os resultados também sugerem Santo André como município prioritário para monitoramento, pois apesar dos resultados pífios que apresentou na presente versão do índice ambiental, vem realizando nos últimos anos esforços consideráveis na implementação de políticas urbanas com uma forte dimensão ambiental, o que se espera irá se refletir em melhoras substanciais neste índice no futuro.

Os resultados obtidos também explicitam tendências, positivas e negativas, que indicam caminhos a ser seguidos. Por exemplo, a rejeição da hipótese de um trade-off recorrente entre desenvolvimento humano e qualidade ambiental e entre os índices de sustentabilidade e o tamanho das cidades, traz bastante alento e indica ser possível trilhar caminhos mais sustentáveis, mesmo regiōes metropolitanas do porte de São Paulo. Por outro lado, é preocupante o grande desnível entre qualidade ambiental e desenvolvimento humano verificado nas capitais e nos municípios fortemente industrializados.

Claramente, existem limitações importantes de dados. A melhoria e ampliação das bases de dados, utilizando-se de dados recém-produzidos e em desenvolvimento, irão trazer avanços consideráveis para versões futuras do SISU. O IBGE publicou recentemente nova base de dados, específica sobre gestão ambiental municipal no Brasil, a qual irá contribuir para a produção de indicadores de capacidade político-institucional mais acurados. Nos próximos 18 meses serão construídos índices para as três regiōes metropolitanas do Estado de São Paulo, que possui bases de dados mais completas, o que possibilitará tanto a incorporação de indicadores importantes ausentes nesta versão, como os de qualidade do ar e do solo, quanto a construção de séries temporais.

A construção de séries temporais é fundamental para se avaliar de forma mais dinâmica o desempenho dos municípios, captando melhorias e retrocessos. Também é imprescindível para que se possa responder adequadamente aos questionamentos em relação à correlação negativa encontrada entre o índice ambiental e o índice de capacidade política. 
Versōes futuras dos índices para poderão também incorporar proxies de qualidade ambiental, as quais podem ser obtidas através da modelação das informações disponíveis de qualidade do ar através de um sistema de informações geográficas, bem como proxies da qualidade do solo urbano, como a ocorrência de acidentes de deslizamentos de terra em áreas urbanas.

\section{Referências bibliográficas}

Acserald H. (1999). "Discursos da sustentabilidade urbana”. Revista Brasileira de Estudos Urbanos e Regionais, 1.

Bourdieu, P. (1996). Razôes práticas: Sobre a teoria da ação. Campinas: Papirus.

Costa, H.S.M. (1995). "Desenvolvimento urbano sustentável: uma contradição de termos?” Revista Brasileira de Estudos Urbanos e Regionais, 2.

Dasgupta, P. et al. (1995). "Environmental regulation and development: a cross country empirical analysis". Policy Research Working Papers, 1448 .

Environmental Sustainability Index (2002). http:/ /www.ciesin.columbia.edu/indicators/ESI/

(2005).

http://www.ciesin.columbia.edu/indicators/ ESI/

Esty, D. e M. Porter (2002). "National Environmental Performance: measurements and determinants". Esty, D. e P. Cornelius, Environmental Performance Measurement: the global report 2001-2002. Oxford Press.

Ferreira, L. (1998). A questão ambiental: sustentabilidade e políticas públicas no Brasil. São Paulo: Boitempo Editorial.

Foulcault, M. (1996). Microfisica do poder. Rio de Janeiro: Editora Graal.

Fundação João Pinheiro (2001). Produto interno bruto de Minas Gerais-municípios e regiōes. Belo Horizonte: FJP.

Fundação Seade (2002). Índice paulista de responsabilidade social. São Paulo: Fundação Seade.

Herculano, S. (1998). "A qualidade de vida e seus indicadores". Ambiente \& Sociedade, 1, 2.

Instituto Brasileiro de Geografia e Estatística (1970). Censo demográfico 1970. Brasília: IBGE.

(1980). Censo demográfico 1980. Brasília: IBGE.
(1991). Censo demográfico 1991. Brasília: IBGE.

(2000). Censo demográfico 2000. Brasília: IBGE.

(2004) Indicadores de desenvolvimento sustentável: Brasil 2004. Brasília: Instituto Brasileiro de Geografia e Estatística.

IPEA/IBGE/Nesur (1999). Caracterização e tendências da rede urbana do Brasil. Campinas: IE-Unicamp.

Isla M.A. (1998). "Review of the urban indicators experience and a proposal to overcome current situation. The application to the municipalities of the Barcelona province". World Congress of Environmental and Resource Economists. Isola de San Giorgio, Venice (Italy), June 25-27.

McGranahan, G. e D. Satterthwaite (2002). “The environmental dimensions of sustainable development for cities". Geography, 87, 3.

Miller, R.B. e C. Small (2003). "Cities from space: potential applications of remote sensing in urban environmental research and policy". Environmental Science \& Policy, 6.

Millennium Ecosystem Assessment (2005). Ecosystems and human well-being: Current state and trends findings of the condition and trends working group. Washington, D.C.: Island Press.

Novaes, W. (coord.) (2000). Agenda 21 brasileira: bases para discussão. Brasília: MMA/PNUD.

OECD (1994). Environmental indicators. Paris: OECD Core Set.

Prescott-Allen, R. (1995). Barometer of sustainability: A method of assessing progress toward sustainable societies. Victoria: Padata.

Paula, J. A. (coord.) (1997). Biodiversidade, população e economia: uma região de Mata Atlântica. Belo Horizonte: UFMG/ CEDEPLAR.

The World Bank (1991). Urban policy and economic development: An agenda for the 1990s. Washington D. C.: The World Bank.

United Nations (1992). Agenda 21 -Rio Declaration. Río de Janeiro: Proceedings of the United Nations Conference on Environment and Development. (2001). Indicators of sustainable development: Guidelines and methodologies. New York: UN. 
Sustentabilidade e condiçôes de vida em áreas urbanas: medidas e determinantes em duas regiōes metropolitanas brasileiras

United Nations Centre for Human Settlements (1988). Global shelter for the year 2000. Nairobi: UNCHS (Habitat).

(2004). Urban indicators guidelines: Monitoring the Habitat agenda and the millennium development goals. Nairobi: UNCHS (Habitat). United Nations Development Programme (1992). The urban environment in developing countries. New York: UNDP.
UNDP/UNCHS/The World Bank (1994). Toward environmental strategies for cities: Policy considerations for urban environmental management in developing countries. Washington D.C.: The World Bank.

Urban World Forum (2002). Reports on dialoguessustainable urbanization. http:// www.unchs.org/uf/aii.html 